\title{
Interpretation of the stiffness and permeability of Sand-Kaolin mixtures in the framework of homogenization
}

\author{
CLAUDE BOUTIN, GREGORY KACPRZAK and THIEP DOANH \\ Université de Lyon, École Nationale des Travaux Publics de l'Etat, LGM/DGCB CNRS 1652 \\ Rue Maurice Audin 69518 Vaulx-en-Velin, France \\ Manuscript received on June 4, 2008; accepted for publication on February 9, 2009
}

\begin{abstract}
This study deals with the behaviour of mixtures of sand and saturated kaolin paste considered as composite materials made of permeable and deformable (with non-linear behaviour) matrix (the kaolin paste) with rigid and impervious inclusions (the sand grains). Oedometric and permeability tests conducted on such mixtures highlight the key role of the state of the clay paste, and show the existence of a threshold of sand grain concentration above which a structuring effect influences both modulus and permeability. At the light of these experiments, the usual and tangent homogenization process (with simplifying assumptions to make the problem manageable) has been applied to estimate the mixture permeability and tangent compressibility. Qualitative and quantitative comparisons with experimental data point out the domain of interest and the limitations of such approaches.
\end{abstract}

Key words: homogenization, non-linear behaviour, sand-clay mixtures, permeability, tangent modulus, compaction, hardening.

\section{INTRODUCTION}

Materials made of sand and clay are widely encountered in civil engineering either as common natural soils on which structures are settled, or as reconstituted materials used for road embankment, earth dam, contamination barrier, etc. Their ability to be compacted is of first importance in design, either to predict or control the structural settlement due to consolidation, or to reach required performances in terms of mechanical resistance or impermeability, particularly in the case of clay liners. From practice, it is well known that the compressibility highly depends on the nature of the constituents - especially the mineralogical structure of the clay their relative proportions, as well as the overall density

Selected paper presented at the IUTAM Symposium on Swelling and Shrinking of Porous Materials: From Colloid Science to Poromechanics - August 06-10 2007, LNCC/MCT.

Correspondence to: Claude Boutin

E-mail: claude.boutin@entpe.fr and the water content. However, if empirical rules are well established, the derivation of the sand-clay mixture compressibility from that of the constituents remains an open question.

This is typically an upscaling problem that could in principle be handle in the framework of homogenization methods. The use of such a framework is, however, made difficult by the strong non-linearity and irreversibility of the compaction process, whose aim is to produce a large reduction in pore volume (and to expel water in case of saturated materials). It is largely accepted in soil mechanics that, for simple soils like uncemented sand or remoulded kaolin recompacted in the laboratory, the decrease in void volume during compaction is proportional to the logarithm of the effective stress $\sigma^{\prime}$ following the phenomenological law:

$$
e_{1}-e_{0}=-C_{c} \cdot \log \frac{\sigma_{1}^{\prime}}{\sigma_{0}^{\prime}}
$$


where $e$ is the void ratio, $C_{c}$ is the compression index and the subscript 0 and 1 denote two arbitrary states.

Actually, even in the basic case of a composite made of saturated clay and rigid sand grains, such a non-linear physics including volume variations as an essential feature leads to homogenization problems of high theoretical and numerical complexity. For this reason, simplifying physically based assumptions are of interest to make the up-scaling problem manageable, while catching the key mechanisms at the local scale.

This study aims at clarifying this question by a twofold approach that consists in, (Kacprzak 2006):

- first, to produce and analyze experimental data in order to identify the key mechanisms of compaction hardening at the inter-granular scale and to derive reasonable assumptions in view of homogenization. For the sake of simplicity, only unidirectional experiments have been performed. Moreover, as linear homogenization is well established, experiments involving both linear (viscous flow) and nonlinear phenomena (consolidation hardening) will be conducted in order to point out the specificity induced by the non-linearity.

- second, to identify up to which extent some usual homogenization processes are able to describe reasonably the mixture behaviour, and, using experiments for comparison, to point out their main limitations.

The paper is divided into four sections. First, the basic principles taken in consideration to develop this study are given. Then, the fabrication procedure of the saturated sand-clay mixtures and the testing program of oedometric and permeability measurements are described. The third section is focused on the experimental results and their physical interpretations. Finally, by using classical and tangent homogenization approaches in association with simplifying assumptions, basic modelling of the mixture permeability and non-linear oedometric compressibility are presented and discussed.

\section{GUIDELINES OF THE STUDY}

This study is devoted to saturated mixtures made of the three following constituents:
- Hostun's sand grains (G), having a density $\rho_{g}$ equal to $2650 \mathrm{~kg} / \mathrm{m}^{3}$, and quasi-uniform size distribution with a $D_{50}$ close to $0.5 \mathrm{~mm}$. The minimum and maximum void ratio of this sand are respectively of $e_{\min }=0.65 ; e_{\max }=1.04$.

- Kaolin (C), having a density $\rho_{c}$ equal to $2650 \mathrm{~kg} /$ $\mathrm{m}^{3}$ and typical size of platelets equal to $5 \mu \mathrm{m}$. The water content at the liquid and plastic limits is equal to $w_{L}=0.51$ and $w_{P}=0.24$, respectively.

- Water (W) having a density $\rho_{w}$ equal to $1000 \mathrm{~kg} /$ $\mathrm{m}^{3}$. Note that the use of kaolin avoids or greatly minimizes any phenomena of swelling induced by water, whatever is its ionic concentration.

The mixtures are macroscopically homogeneous, and the characteristic size of their Representative Elementary Volume (REV) is much smaller than the size of the samples tested for this study.

\section{TRIANgular REPRESENTATION OF SATURATED} MiXTURES

For saturated mixtures, the volume ratio of grains $G$, clay platelets $C$, and water $W$, defined by:

$$
\begin{aligned}
C & =\frac{V_{C}}{V_{C}+V_{G}+V_{W}} ; \\
G & =\frac{V_{G}}{V_{C}+V_{G}+V_{W}} ; \\
W & =\frac{V_{W}}{V_{C}+V_{G}+V_{W}},
\end{aligned}
$$

are related by:

$$
C+G+W=1,
$$

and the water volume ratio $W$ is the usual porosity $n$.

Conveniently, any mixture may by represented by a point $\mathbf{M}$ in an equilateral triangle $\{\mathbf{C}, \mathbf{G}, \mathbf{W}\}$ whose summits $\mathbf{C}, \mathbf{G}, \mathbf{W}$ correspond respectively to $C=1$, $G=1, W=1$, and the opposite basis, e.g. $\mathbf{G W}$, corresponds to $C=0$, (and $\mathbf{C W}$ to $G=0 ; \mathbf{C G}$ to $W=0$ ). The three volume ratios of the mixture represented by $\mathbf{M}$ are provided by the three orthogonal projections of $\mathbf{M}$ on the three altitudes (Fig. 1 on the left).

The clay content ratio $R_{c}$ that determines the grains size distribution of the mixture (either in terms of mass 

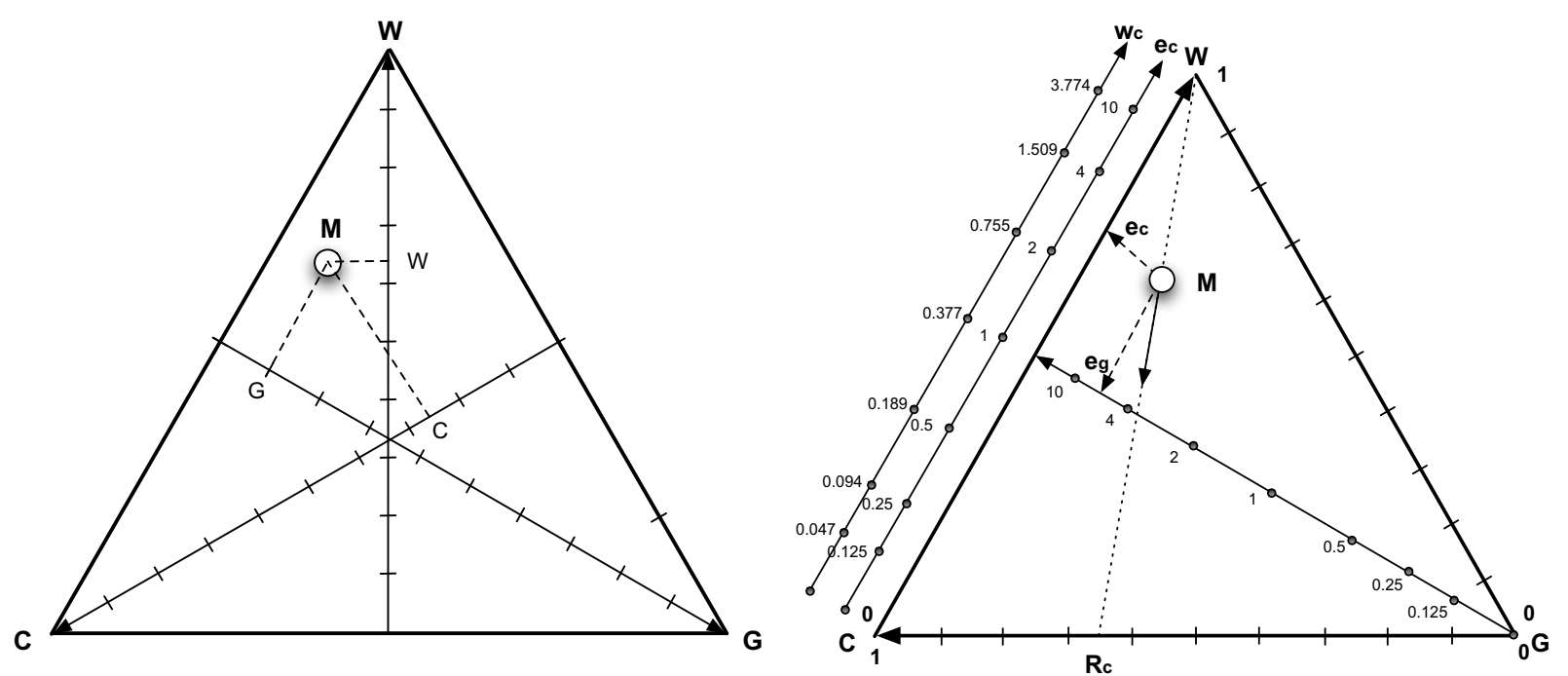

Fig. 1 - Triangular representation of saturated sand clay mixtures. On the left, determination of the mixture composition with of the volume ratio parameters $C, W, G$. On the right, identification of the two control parameters $e_{c}$ and $e_{g}$. The extended line WM corresponds to mixtures of identical $R_{C}$ and indicates the consolidation path in oedometer testing.

or volume, since the grains and platelets specific gravities are identical) is defined by:

$$
R_{c}=\frac{C}{C+G}
$$

Graphically, $R_{c}$ is obtained by the intersection of the line WM with the base CG. (Fig. 1 right). Note that all mixtures located on the line WM have the same clay content ratio, i.e., the same constitution of solid particles (and, therefore, same grain size distribution). For this reason, during its oedometric consolidation, a mixture necessarily evolves on the line WM.

The void ratio $e$ of the saturated mixture is given by:

$$
e=\frac{W}{C+G}=\frac{W}{1-W} .
$$

It is obtained in the triangular graph - with a non-linear scale - by the projection of $\mathbf{M}$ on the altitude issued from the vertex $\mathbf{W}$, perpendicular to $\mathbf{C G}$. Thus, all mixtures located on a line parallel to CG have an identical void ratio $e$, or also the same porosity $n=W$.

\section{The two control parameters $e_{c}$ and $e_{g}$}

Because of the great difference of size between sand grains and kaolin platelets, such mixtures can be considered as bi-composite materials made of sand grains embedded in a matrix of saturated clay paste (i.e., kaolin and water). These two components present highly contrasted properties, since the grains are rigid and impervious while the clay paste is deformable and permeable.

The mechanical properties of the clay paste strongly depend of its water content $w_{c}$. The behaviour ranges from that of a quasi-liquid suspension for $w_{c}>w_{L}$ (undrained shear strength $c_{u}$ typically less than $2 \mathrm{kPa}$, (Wood 1990)) to that of a plastic paste for $w_{L}>w_{c}>$ $w_{P}$ (undrained shear strength typically comprised between 2 and $200 \mathrm{kPa}$ ), and reaches a solid behaviour for $w_{c}<w_{P}\left(c_{u}\right.$ typically higher than $\left.200 \mathrm{kPa}\right)$. When the shrinking limit $w_{S}<w_{P}$ is reached, the arrangement of the clay platelets cannot adapt anymore to the weak amount of water and the saturation is no more possible. In this state, the behaviour of the material is progressively affected by other mechanism such as suction by desaturation, and cracks start to develop.

The density of the mixture obeys moreover to restrictions imposed by the sand skeleton. Sand grain arrangement in the mixture cannot be denser than the densest arrangement of pure sand alone $\left(R_{c}=0\right)$, but oppositely, can be looser than the loosest arrangement of pure sand. Then, considering the paste to grain volume ratio, $e_{g}=(C+W) / G$, (Mitchell 1976):

- necessarily $e_{g}>e_{\min }$;

- when $e_{\max }>e_{g}>e_{\min }$, one may infer that the grains are in contact and constitute a skeleton; 
- the larger the grain volume ratio $e_{g}\left(>e_{\max }\right)$, the lower the contacts among grains will be. As a consequence, grains do not build a skeleton and the mixture turns to a clay paste matrix embedding dispersed grains.

These observations lead to the use of the two volumetric control parameters $e_{c}$ and $e_{g}$ for specifying the mechanical behaviour of the mixtures:

- the clay paste void ratio defined by:

$$
e_{c}=\frac{W}{C},
$$

is related to the water content of the paste (defined in terms of mass ratio) by $e_{c}=\left(\rho_{c} / \rho_{w}\right) w_{c}=$ $2.65 w_{c}$. In the triangular graph, $e_{c}$ is obtained with a non-linear scale - by the intersection of the line GM with the base CW (Fig. 1 on the right). Note that all mixtures located on the line GM have the same clay void ratio, i.e., the same clay behaviour at the initial state.

- the granular "void" ratio related to the concentration in grains. By analogy with pure sand, the granular void ratio is the ratio of the volume in-between sand grains divided by the volume of grains in a unit volume of mixture. Its expression is:

$$
e_{g}=\frac{C+W}{G}=\frac{1-G}{G} .
$$

As $e_{g}$ is a function of $G$, its representation in the triangular graph lies on the same axis than $G$ (i.e., the projection of $\mathbf{M}$ on the line perpendicular to the base $\mathbf{C W}$, Fig. 1 on the right), but with a nonlinear scale (Fig. 1 on the left). Consequently, all the mixtures located on a line parallel to $\mathbf{C W}$ have identical granular void ratio.

\section{MiXture Composition and Mechanical Behaviour}

By crossing the features of sand $\left(e_{\min }, e_{\max }\right)$ and of clay paste $\left(w_{L}, w_{P}, w_{S}\right)$, one may define different morphologies of the mixtures (Fig. 2).

Three regions are defined by the two lines parallel to $\mathbf{C W}$ corresponding to $e_{g}=e_{\min }$ and $e_{g}=e_{\max }$. Mixtures of $e_{g}<e_{\min }$ are impossible to happen, between the lines $e_{g}=e_{\min }$ and $e_{g}=e_{\max }$ they present a granular skeleton, and between $e_{g}=e_{\max }$ and $\mathbf{C W}$, their morphology turns progressively to dispersed grains into a clayed matrix.

The lines GL, GP, GS corresponding to $w_{c}=w_{L}$, $w_{P}, w_{S}$ define four sectors. In between $\mathbf{G W}$ and $\mathbf{G L}$, the clay paste behaves as a quasi-liquid suspension; in between GL and GP, the clay paste behaves as a plastic paste; in between GP and GS, the clay paste is solid. Finally, in between GS and GC, it is impossible to saturate the clay and therefore, the mixture. The shaded regions in Figure 2 below $e_{\min }$ and $w_{S}$ indicate the impossible states of saturated sand-clay mixtures.

From this representation it is clear that, by modifying the amount of water, mixtures made of the same sandy clay material may range from a quasi-liquid suspension of clay with dispersed sand grains (that may even be unstable because of the sand grains sedimentation) to a sand skeleton surrounded by a plastic paste. Similarly, at the same porosity (or void ratio), by changing the sand content, the mixture may vary from a clayed sand made of a solid clay matrix embedding sand grains, to a sandy clay having a grain skeleton surrounded by a plastic paste.

These two examples show that, when varying independently the usual soil mechanics parameters $e$ (or $W$ ) and $R_{c}$, both clay water content and sand content are modified. Thus, the links between the behaviour of the constituents and the one of the mixture would be difficult to identify. For this reason, in this study, the mixtures have been created in view of controlling the paste behaviour - by $w_{c}$ or $e_{c}$ - and the sand content, by $e_{g}$.

\section{TESTED MIXTURES AND EXPERIMENTS}

More than twenty mixtures have been done (Kacprzak 2006). Three initial water contents $\left(w_{c i}\right)$ were selected to study mixtures made of paste either at the liquid limit $\left(w_{c i}=w_{L}=0.51 ; c_{u} \approx 2 k P a\right)$, at an intermediate water content $\left(w_{c i}=0.35 ; c_{u} \approx 31 k P a\right)$, and close to the plastic limit $\left(w_{c i}=0.30>w_{P}=0.24 ; c_{u} \approx\right.$ $73 k P a)$, Figure 3. The grain size distribution of the tested mixtures is shown in Figure 4 . Values of $e_{g}$ close to $e_{g} \approx 1 \approx e_{\max }, 1.5,2,3,4,6$ and $\infty$ (no sand) have been chosen to investigate mixtures where grains may be in contact or are dispersed in the paste in a "dense" or more diluted concentration. 


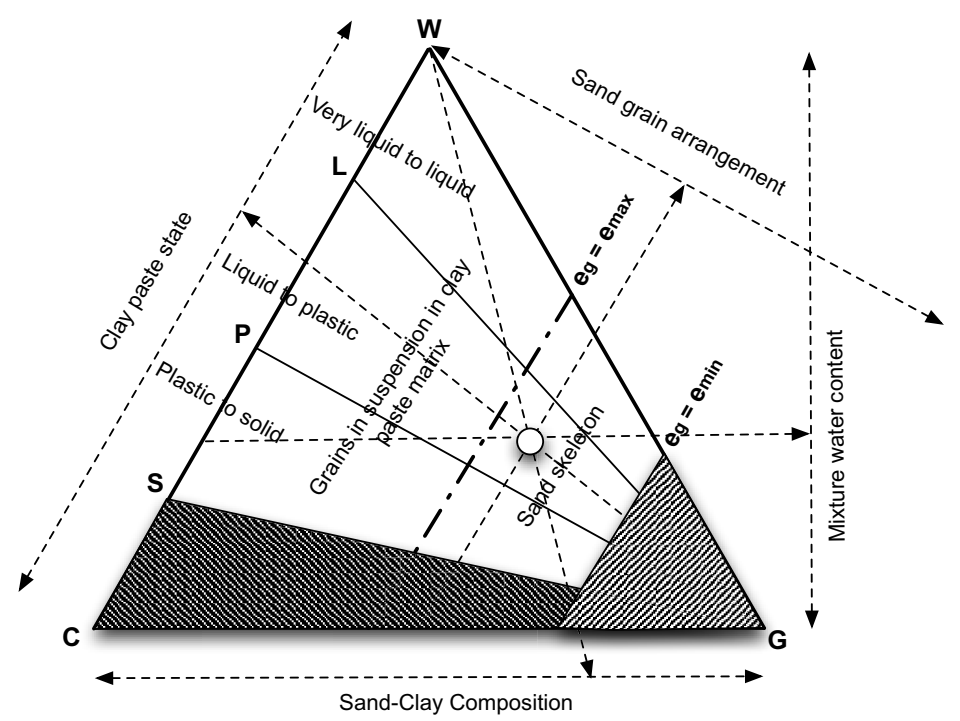

Fig. 2 - Possible morphology of saturated sand-clay mixtures.

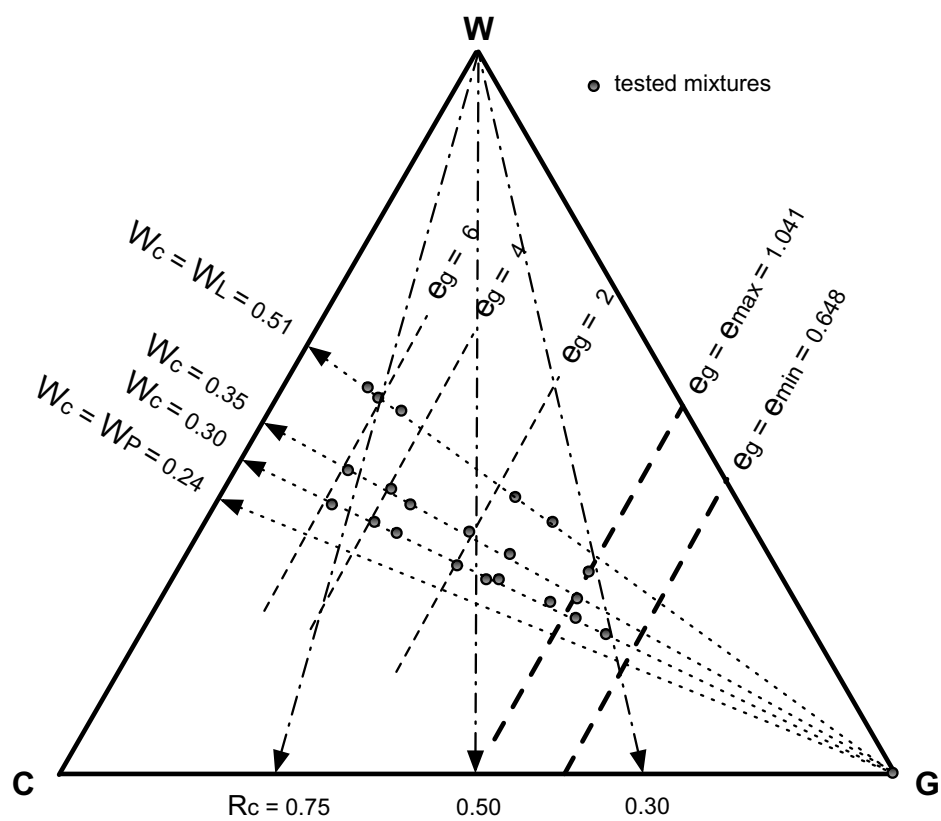

Fig. 3 - Triangular representation of the tested sand clay mixtures.

\section{FABRICATION PROCEDURE}

A reliable fabrication procedure has been defined and followed cautiously for all tested mixtures. First, the kaolin powder is mixed thoroughly with distilled water added progressively in a 5 litres mechanical mixer. The combined effects of mixing and slowly water impregnation yields easily to homogeneous saturated pastes with the target initial water content $\left(w_{c i}\right)$. Then, an appropriate amount of Hostun sand was added progressively to this clay paste at the required state $\left(w_{c i}\right)$ and slowly mixed to reach a target value of $e_{g}$. Observations indicated that this procedure leads to a mixture formed by sand particles uniformly coated by the clay paste. However, air remains in between the spheroid coated grains (except in the case of liquid paste and small amount of sand).

Material is finally compacted using a Proctor dynamical compaction (only half of the standard number 


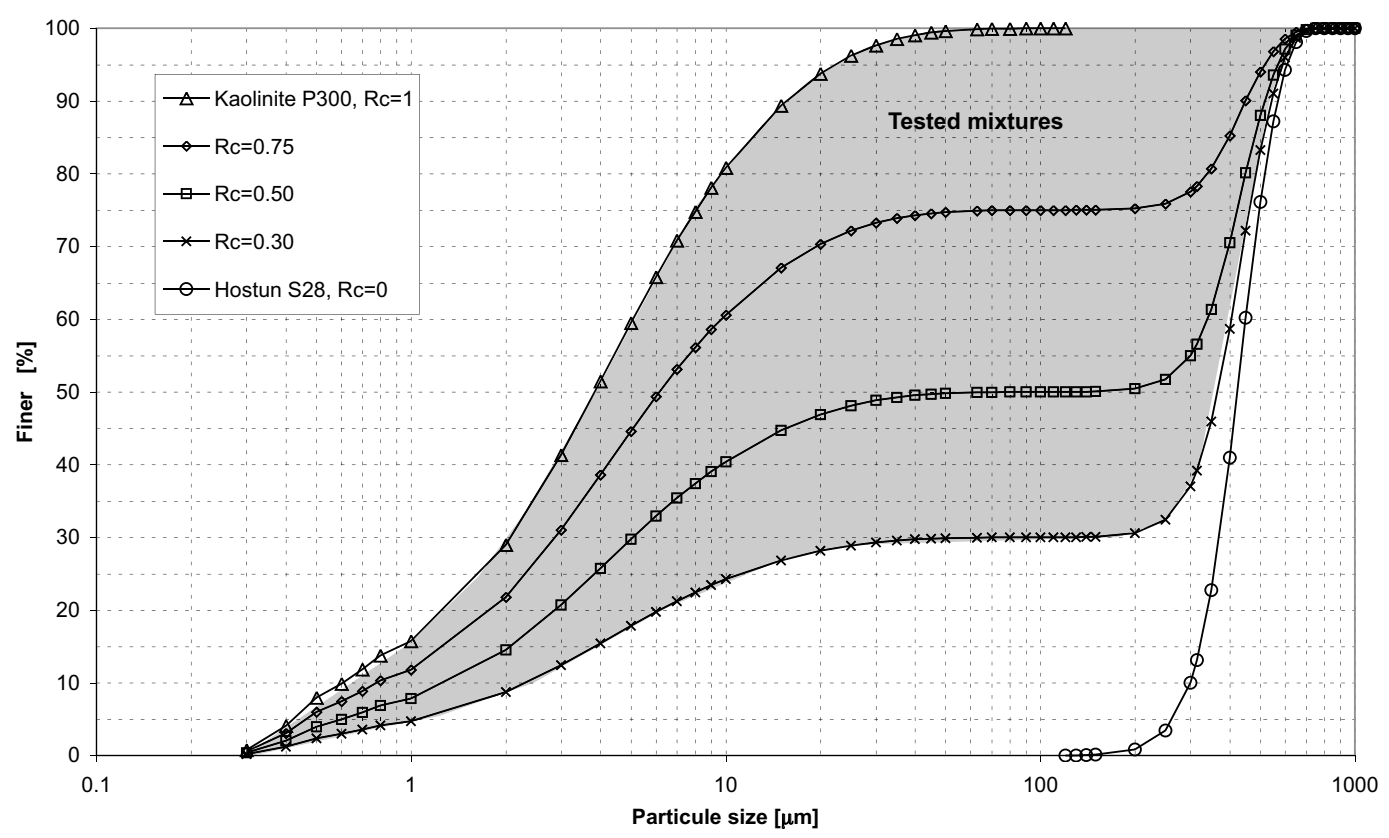

Fig. 4 - Range of variation of grain size distribution of mixtures.

of blows were applied to avoid a high level of pre-consolidation (AFNOR 1993)). The reproducibility of the tests results further carried out on these samples let us be confident about the homogeneity of each specimen and the uniformity of sample population.

It is worth mentioning that, despite the saturation of the clay paste in the first fabrication stage, air bubbles remain trapped during compaction. The checking and loading tests further carried out evidenced the presence of a volume of air around $10 \%$ of the overall volume of the mixture. In the following, to avoid any ambiguity, the term "mixture" systematically specifies the saturated clay, water and sand media (on which the parameter and notations introduced above apply), when "soil" denotes the mixture together with the air bubbles (whose associated parameters are indexed by "s"). The term "pure" refers solely to one constituent of the mixture, i.e., pure sand means only sand in the mixture $\left(R_{c}=0\right)$.

\section{Previous STUdies}

Surprisingly, there are relatively few systematic studies on the response of clay-sand mixtures for different mixture density, water content and clay-sand ratio. Georgianou et al. (1990) study the response of Ham river sands merged in a very liquid speswhite kaolin slurry $\left(5 w_{L}\right)$, and found that the mixture behaves almost as a sand saturated by pure water. This result indicates that, for such a high level of clay paste liquidity, suspensions of sand grains are unstable, so that mixtures necessarily present a skeleton of sand grains. Wood and $\mathrm{Ku}-$ mar (2000) investigate mixtures made of a liquid kaolin clay $\left(1.5 w_{L}\right)$ and coarse sand. They establish two kinds of behaviour: the behaviour of stable suspensions of grains, mainly controlled by the clay paste, and the behaviour of skeletons of grains in contact filled by the clay paste, mainly controlled by the grains. The conclusions drawn in this study are, however, limited to the case of clay paste with a water content higher than the liquid limit, that is with a very low shear strength. As a consequence, the clay paste cannot carry shear forces and cannot consequently act as bridges in-between the sand particles. The aim of the present study is to provide some insights into the behaviour of clay-sand mixtures where the stiffness and the strength of the clay paste range from low values to values close to that of the sand skeleton.

\section{EXPERIMENTS}

From the Proctor mould (inner diameter of $10.19 \mathrm{~cm}$, height of $11.65 \mathrm{~cm}$ ), three cylindrical samples (diameter of $7.14 \mathrm{~cm}$, thickness of $2.0 \mathrm{~cm}$ ) are extracted. One 


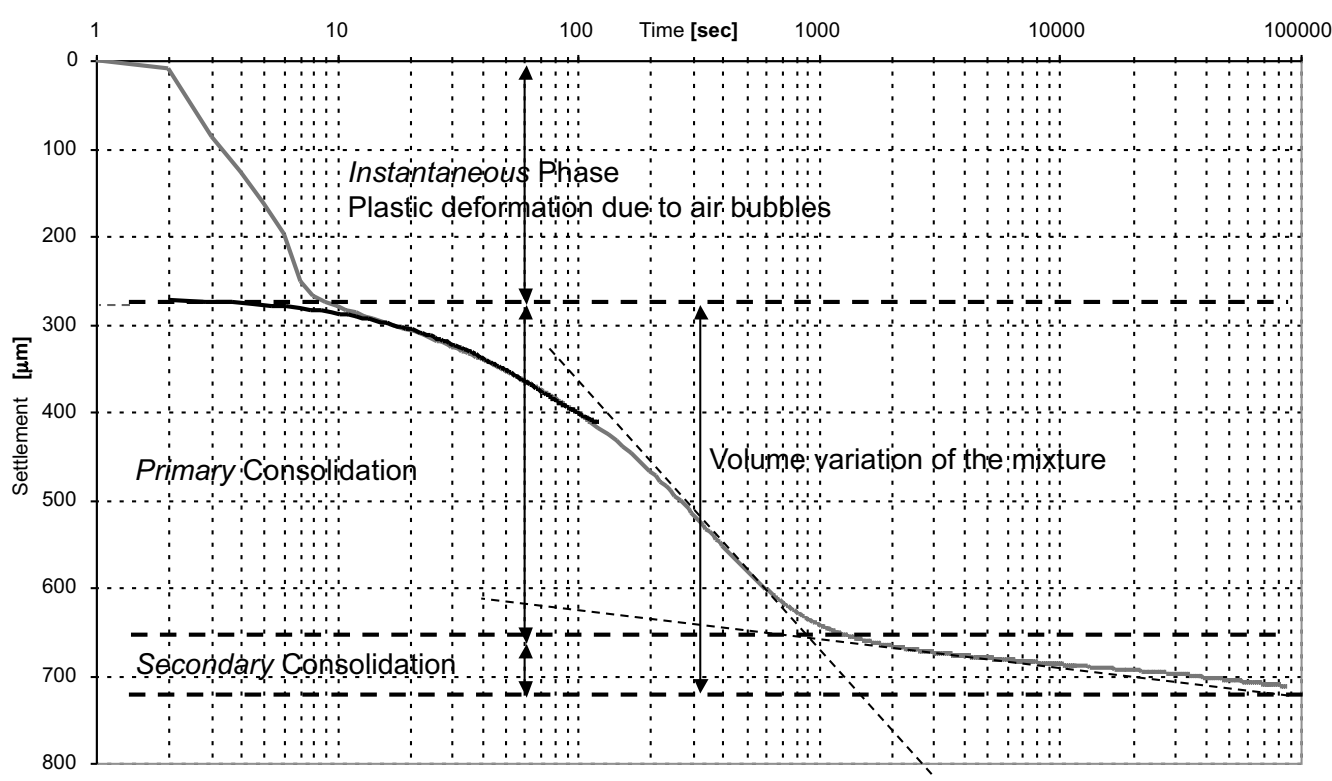

Fig. 5 - Typical record of settlement versus $\log (t)$ for a single loading stage, separated into three mechanisms decoupled in time.

sample was used for checking the values of targeted $e_{c}$ and $e_{g}$. The two others were submitted to identical oedometric tests (AFNOR 1997) and permeability measurements (AFNOR 2005). A fairly good reproducibility of the experimental results is systematically noticed.

The oedometric experiments follow the standard procedure, doubling the load every 24 hours, from $35 \mathrm{kPa}$, to $1120 \mathrm{kPa}$. Including the intermediate (280$70 \mathrm{kPa}$ ) unloading-reloading, and final unloading steps (1120-35 kPa), the experiments took 14 days. The settlement of the sample was measured automatically by LVDT sensors.

The permeability measurements have been performed straightforwardly on the samples in the oedometric cell before each additional loading step using the variable head method. The ambient temperature was also monitored in the oedometric cell.

\section{ANALYSIS AND TREATMENT OF EXPERIMENTAL DATA}

\section{RESULTS FROM OEDOMETER LOADING}

The record of the settlements observed during all the oedometer tests and for all the loading stages systematically evidence three different steps (Fig. 5).

Initially, an instantaneous high deformation is observed. Further unloading indicates that this deformation is irreversible. Because clay, grain and water are weakly compressible, an instantaneous seepage is impossible. Moreover, the adjustment of mechanical gaps in the apparatus only concerns the first loading step. Thus, this systematic quick volume variation results from the compression of the very deformable air bubbles captured inside the soil during the sample preparation: under a load increment, the paste instantaneously yields, compresses the air bubbles, and the soil reaches a more compact configuration that supports the total applied load.

In a second step, the classical phase of consolidation starts to develop. It corresponds to the transfer of load from the fluid to the solid, associated with the expulsion of water that induces the volume variation. In good agreement with the consolidation theory, it has been observed that the duration of the primary consolidation and the magnitude and rate of settlements increased for samples with a higher void ratio of the clay paste and a lower granular void ratio.

The third step consists in the secondary consolidation, characterized by a linear evolution of the settlements with $\log (t)$. By testing the different mixtures, it has been noticed that the amplitude of this phase increases with the void ratio of the clay paste. Moreover, when $e_{g}$ is close to $e_{\max }$ (i.e., when the grains are in contact and forms a continuous skeleton), the magnitude of the 
secondary and primary consolidation have been observed to be comparable.

\section{Mean Clay Paste Void Ratio $<e_{c}>$ and Apparent CLAY COMPRESSIBILITY}

It can be deduced from Figure 6 that all the tested soils follow the classical one dimensional consolidation behaviour as all the compression curves are straight lines in the $e_{s}-\log \left(\sigma^{\prime}\right)$ diagram. However, they do not allow for a good discrimination of the behaviour of the different soils. A better insight into this question is presented hereinafter by drawing the compression curve of the mixture and the apparent compression curve of the clay paste within the mixture.

At each loading stage, the effective volume variation of the saturated sand clay mixture is calculated by subtracting the instantaneous settlement (due only to air bubbles compression) from the total settlement of the soil. This procedure enables the derivation of the average void ratio of the saturated mixture, denoted $<e>$ :

$$
<e>=\frac{W}{C+G}
$$

and the drawing of the mixture compression curve $<e>$ versus $\log \left(\sigma^{\prime}\right)$.

Now, the average void ratio of the clay paste $\left\langle e_{c}\right\rangle$ can be obtained by dividing $\langle e\rangle$ by the clay content $R_{c}$, which is constant during each oedometric tests:

$$
\frac{<e>}{R_{c}}=\frac{W}{C+G} \frac{C+G}{C}=\frac{W}{C}=<e_{c}>
$$

Then, the apparent compression curve $\left(\log \left(\sigma^{\prime}\right) ;<e_{c}>\right)$ of the clay paste within the mixture, can be deduced as shown in Figure 7. The term "apparent" underlines that, in most of the cases, the effective stress $\sigma^{\prime}$ applied on the mixture is not the stress supported by the clay itself. The following paragraphs address the analysis of the behaviour of the different mixtures from the analysis of the apparent compression curve of the clay paste only. The discussion is organized by distinguishing the effect of the initial water content of the clay paste (from the liquid to the plastic limit) and the granular void ratio (from dilute to dense).

\section{Mixtures made of clay paste at the liquid limit}

Figure 7(a) shows the apparent compression curve of the clay paste within a mixture at the liquid limit and for different granular void ratio $\left(e_{g}=1,1.2,1.7,3,5,9\right)$, and the compression curve of the pure clay paste. Mixtures with $e_{g} \geq 2 e_{\max }$, that is with sand grains dispersed in the clay paste, have the same apparent compression curve than the pure clay paste. This suggests that the effective stress applied to the mixture $\left(\sigma^{\prime}\right)$ is merely transferred to the clay paste that supports (at least in average) the load applied to the mixture $\left.\left(<\sigma_{c}^{\prime}\right\rangle=\sigma^{\prime}\right)$. Two reasons can be argued for the negligible effect of rigid sand inclusions on the clay paste. The first reason relies on the fact that the grains are too distant to interact significantly. The second reason relies on the low shear strength of the clay paste that avoids the development of shear stresses in the paste. As a result, the stress state inside the clay is very close to be uniformly hydrostatic within all the sample. Both the local vertical stress $\left\langle\sigma_{c}^{\prime}\right\rangle$ and the local void ratio of the clay paste are homogeneous in the sample and equal, respectively, to the vertical applied load $<\sigma^{\prime}>$ and average void ratio of the clay paste $\left\langle e_{c}\right\rangle$. Thus, $\sigma_{c}^{\prime}=\sigma^{\prime}$ and $<e_{c}>=e_{c}$, the compression curves $\left(\log \left(\sigma^{\prime}\right) ;<e_{c}>\right)$ and $\left(\log \left(\sigma^{\prime}\right) ; e_{c}\right)$ coincide.

Oppositely, the mixture that presents a skeleton of grains, $e_{g}=1=e_{\max }$, shows an apparent compression curve close to that of the loose sand, much less compressible than the pure clay paste. The reason is that the grain skeleton - significantly stiffer than the liquid clay paste - supports most of the stress applied to the mixture $\left(\sigma_{s k}^{\prime} \approx \sigma^{\prime}\right)$. Thus, the clay paste undergoes locally small stresses $\left(\sigma_{c}^{\prime} \ll \sigma^{\prime}\right)$ and its volume variation is essentially governed by the grain rearrangement. Consequently, the volume variations of the pure clay paste are much smaller than those that would have suffered by carrying the whole mixture stress.

Finally, the apparent compression curve of the mixture with a granular void ratio $e_{g}=1.2$ lies in between those of the pure clay paste and the mixture of loose sand $\left(e_{g}=e_{\max }\right)$ - clay paste. In this intermediary case, despite of a sand skeleton being in formation (not all the grains are in contact as $e_{g}>e_{\max }$ ) the mixture is able to carry a load that the clay paste alone could not support. This stiffening effect is interpreted as due to the 


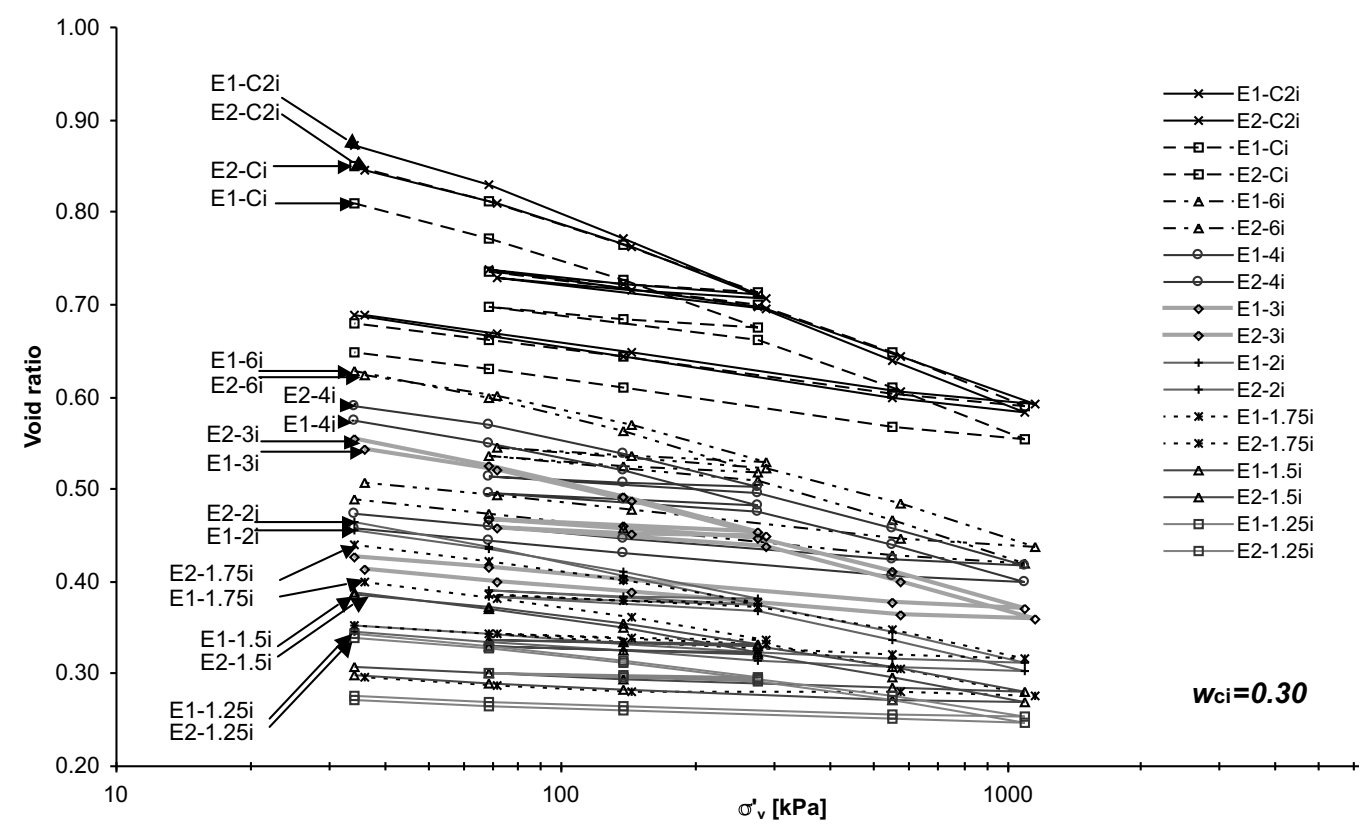

Fig. 6 - Compression curves $\left(e_{s} ; \log \left(\sigma^{\prime}\right)\right)$ obtained for the soil samples prepared with $w_{c}=0.30$ and $e_{g}=1.25,1.5,1.75,2,3,4,6$, and the pure clay paste. The superimposed curves are an evidence of the good repeatability of the results.

existence of a tenuous skeleton made of sand grains already in contact and clay bridges that undergo stresses of the same order $\left(\sigma_{k}^{\prime} \approx \sigma_{c}^{\prime}\right)$. Due to load partly carried by the tenuous skeleton and partly by the clay paste, both having comparable stiffnesses, the stress within the paste differs from that applied to the mixture and the apparent compression curve differs from that of pure clay paste.

These results are qualitatively identical to those obtained by (Wood and Kumar 2000) for mixtures of similar constitution. Both studies indicate that the behaviour "jumps" from that driven by the clay paste to that driven by the grain skeleton for a limited increase in granular void ratio. The connection threshold of the grains is the determining factor. The present study indicates that, for the case of a clay paste at the liquid limit, the connection threshold takes place for a granular void ratio ranging between $1.5 e_{\max }$ and $2 e_{\max }$.

\section{Mixtures made of clay at an intermediate state}

Figure 7(b) shows the apparent compression curves of mixtures of different granular void ratio $\left(e_{g}=\right.$ $1,1.5,2,3,4,6)$, made of clay paste at water content $w_{c}=0.30$, an intermediate value between the liquid and plastic limits. They are regularly distributed, ranging from that of pure clay paste and that of loose sand, as the sand concentration increases, i.e., $e_{g}$ decreases. It is worth mentioning that, in all the cases, the presence of sand modifies the apparent compression curve, even at a very low concentration $\left(e_{g}=6\right)$. This last case is particularly interesting as it provides keys about the homogeneity of the stress state inside the clay paste. Indeed, as mentioned above, when the grains are dispersed, the clay paste undergoes in average the load applied to the mixture $\left.\left(<\sigma_{c}^{\prime}\right\rangle=\sigma^{\prime}\right)$. If the stress state would be homogeneous, then, there would be a uniform volume variation of the clay paste and the average void ratio $\left\langle e_{c}\right\rangle$ would be equal to that of the pure clay paste $e_{c}$. As a consequence, the apparent and the pure clay paste compression curves would coincide. As it is not case, one can conclude that the stress state and the volume variations within the clay paste are heterogeneous.

By comparing with the previous case, the explanation for the occurence of heteregeneous stress and strain states can be found in the higher shear strength of the clay paste. It allows the clay to carry the shear forces induced by the presence of the grains: compression zones can develop between two grains along the direction of 


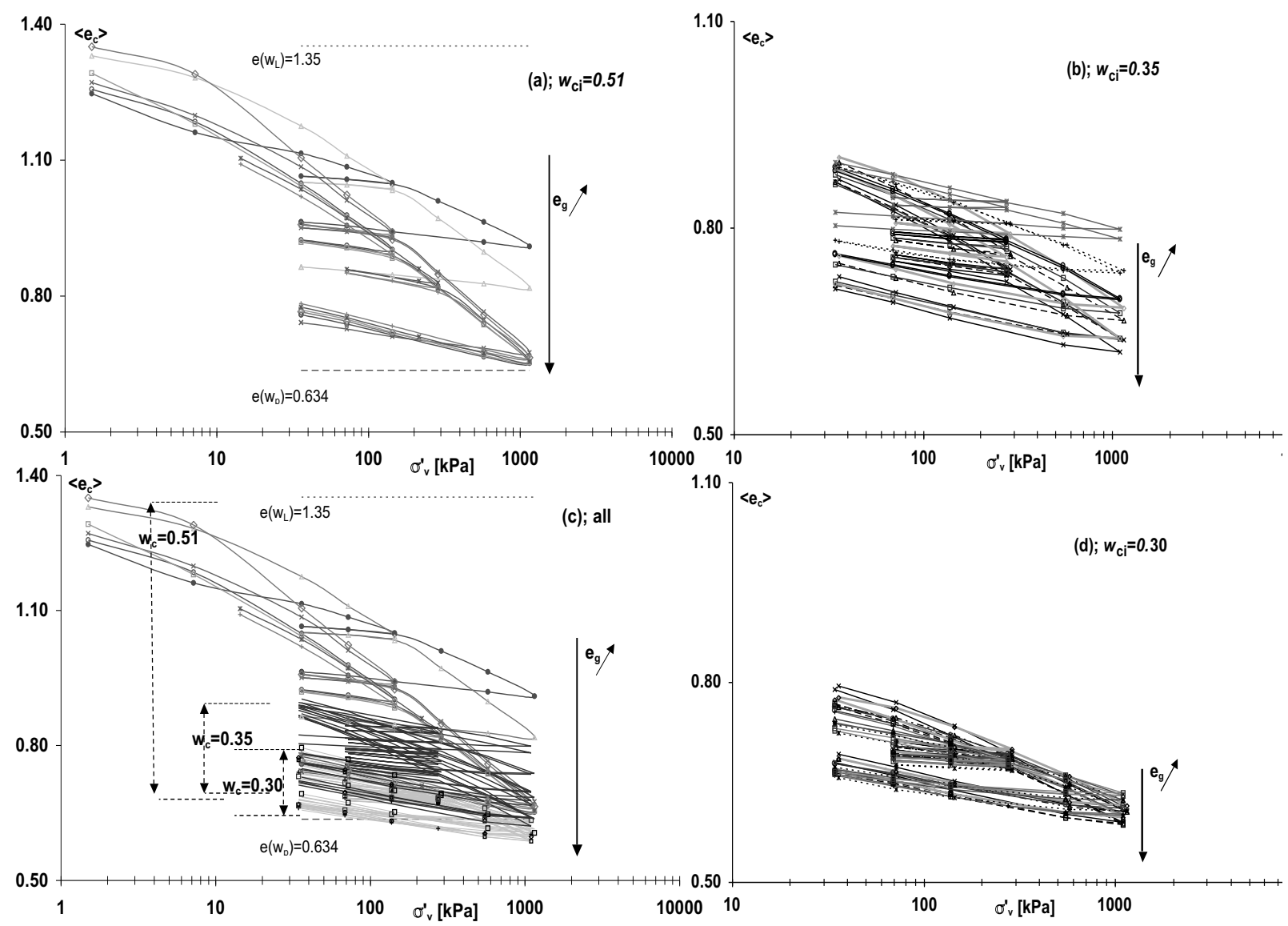

Fig. 7 -Apparent compression curves $<e_{c}>$ versus $\log \left(\sigma^{\prime}\right)$ of the clay within the mixture. Mixtures initially made of clay paste at the liquid state: $w_{c}=0.51 ; e_{g}=1,1.2,1.7,3,5,9,(\mathrm{a})$, at an intermediate state: $w_{c}=0.35, e_{g}=1,1.5,2,3,4,6,(\mathrm{~b})$ and at a quasi-plastic state: $w_{c}=0.30$, $e_{g}=1.25,1.5,1.75,2,3,4,6$, (d). The data of all samples are plotted together on (c).

the load and shear zones between grains shifted one each other with respect to this direction. As (i) the representative elementary volume (REV) undergoes a uniform vertical displacement, and (ii) the grains are rigid, the local axial deformation of the clay paste tends to be in inverse proportion of the inter-grains distance in the loading direction. Because the clay can support shear, this deformation is not compensated by an equivalent lateral deformation. Thus, the clay paste is more loaded in the narrow inter-grains spaces than in larger spaces. As a result of this mechanism, locally denser zones will be created in the clay. Such heterogeneous local stress distributions in heterogeneous media have been already put forward in particular for elastic composites (SanchezPalencia 1980). It explains why, even in absence of a skeleton, the apparent behaviour - related to a local het- erogeneous state - is stiffer than that of the pure clay paste under homogeneous load.

In addition, because of the non-linear hardening behaviour of the clay paste, the denser zones are stiffer than the less compacted zones. This creates a mechanism of local structuring of the clay paste in the REV as bridges of stiffer clay develop in-between the sand grains along the direction of load. This mechanism gets amplified at each loading stage, as the stresses tend to transit through the paths of higher stiffness, i.e., through the already denser local zones of the clay paste, and leaves the other zones less loaded. The structuring process will, thus, lead to the development of stable chains of forces - even in the absence of contacts among sand grains that will carry more and more effort as the external stress increases. The zones within the chain of forces know a 
local stress $\bar{\sigma}_{c}^{\prime}$ higher than the stress externally applied $\sigma^{\prime}$ and a local void ratio $\bar{e}_{c}$ lower than the average void ratio of the clay paste $\left\langle e_{c}\right\rangle$, meanwhile other clay zones remain weakly loaded $\left(\underline{\sigma}_{c}^{\prime} \ll \sigma^{\prime}\right)$, then weakly compacted $\left(\underline{e}_{c}><e_{c}>\right.$ ). Clearly, the effect of such a structuring process is to increase the apparent stiffness of the mixture. One may infer from the test results that the higher is the grain concentration, local denser zones become more and more stressed and, consequently, more and more compact and stiffer, and the more plastic is the paste (i.e., more able to sustain deviatoric stress), the more dominating will be this effect.

One may finally notice that the higher stiffness observed in Figure 7(b) for the mixture $e_{g}=1$, possibly results from the presence of a loose skeleton. The explanation is similar to that proposed for the liquid clay paste.

\section{Mixtures made of clay close to the plastic limit}

Figure 7(d) shows the variation of the apparent compression curves for a mixture made of a clay paste close to the plastic limit $w_{c i}=0.30$ and granular void ratios ranging between $e_{\max }$ and $6 e_{\max }$. It evidences that the apparent compressibility decreases as the granular void ratio increases, in a qualitative way similar to that observed in the other tests. However, the effect of granular void ratio seems to be much more limited. This can be attributed to the higher stiffness of the clay paste, close to that of the sand skeleton. As the stiffness of the mixture can vary only between that of the pure clay and the pure sand, its variation is necessarily limited.

\section{Tangent Oedometric Modulus of MiXtures}

An alternative analyse of the mixture behaviour is to relate the tangent oedometric modulus of mixture $E_{\text {oed }}$ to the mean clay paste void ratio $\left\langle e_{c}\right\rangle$ for different values of $e_{g}$. At each loading stage characterized by $\sigma_{i}^{\prime}$ and $e_{i}=R_{c} .<e_{c}>_{i}, E_{\text {oed }}\left(e_{i}\right)$ is classically deduced from the mixture compression curve $\left(e ; \log \left(\sigma^{\prime}\right)\right)$ by:

$$
E_{\text {oed }}\left(e_{i}\right)=\frac{\triangle \sigma}{\Delta e}\left(1+e_{i}\right)
$$

The results given on Figure 8 show that, for a fixed $e_{g}, \log \left(E_{\text {oed }}\right)$ is a linear decreasing function of $<e_{c}>$. Moreover, as $e_{g}$ increases, $\log \left(E_{\text {oed }}\right)$ increases. This remarkable linearity indicates that the roles played by $e_{c}$ and $e_{g}$ on the mixture behaviour can be expressed in the general empirical form:

$$
\begin{gathered}
\log \left(E_{\text {oed }}\right)=a\left(e_{g}\right)-b\left(e_{g}\right) .<e_{c}>, \\
\quad \text { or } \quad E_{\text {oed }}=F\left(e_{g}\right) \cdot 10^{-<e_{c}>\cdot b\left(e_{g}\right)}
\end{gathered}
$$

The coefficient $b\left(e_{g}\right)$ ranges from 4 for very compressible pure clay pastes, $e_{g}=\infty$ to 10 for stiff mixtures (presenting a grain skeleton, $e_{g} \approx e_{\max }$ ).

For mixtures free of skeleton $\left(e_{g}>2 e_{\max }\right)$, the relation (11) can be specified more precisely from Figure 8. Almost independently of the clay paste state, the value of $\log \left(E_{\text {oed }}\right)$ can straightforwardly be deduced from that of the pure clay paste $E_{\text {paste }}\left(<e_{c}>\right)$ by a translation factor depending on $e_{g}$ :

$$
\begin{gathered}
\log \left(E_{\text {oed }}\right)=a\left(e_{g}\right)+\log \left(E_{\text {paste }}\left(<e_{c}>\right)\right), \\
\text { i.e. } \quad E_{\text {oed }}=F\left(e_{g}\right) \cdot E_{\text {paste }}\left(<e_{c}>\right)
\end{gathered}
$$

The empirical equation (12) uncouples the rheological effect (clay paste response) and the geometrical effect (distance in-between sand grains related to their concentration) in the expression of the stiffness of the mixture. Note that $\left\langle e_{c}\right\rangle$ represents the average void ratio of the clay paste computed during loading for a given mixture, and is not representative of the initial water content of the clay. As well, Figure 8 indicates that $F\left(e_{g}\right)$ and $E_{\text {paste }}\left(<e_{c}>\right)$ take different forms depending of the initial state of the clay paste. For instance, in the case of paste prepared at the liquid state, $E_{\text {paste }}$ is found to follow the relationship:

$$
E_{\text {paste }}\left(<e_{c}>\right)=10^{5} 10^{4\left(1-<e_{c}>\right)}
$$

and $F\left(e_{g}\right)$ ranges from 1 for $e_{g}=\infty$, to 3 for $e_{g}=2$.

For the mixtures with skeleton and/or possible structuring effect $\left(e_{g}<2 e_{\max }\right)$, the roles of $e_{g}$ and $\left.<e_{c}\right\rangle$ are systematically coupled. This illustrates the interdependences of the rheological and geometrical effects that exist in most of non-linear material.

\section{ANALysis of the RESUlts on PERMEability}

A similar analysis has been performed to relate the mixture permeability $K(\mathrm{~m} / \mathrm{s})$ to the pure clay paste permeability $K_{\text {paste }}$ and the sand content. Because of the small amount of air (around $10 \%$, as previously discussed), its influence on the water flow is considered 

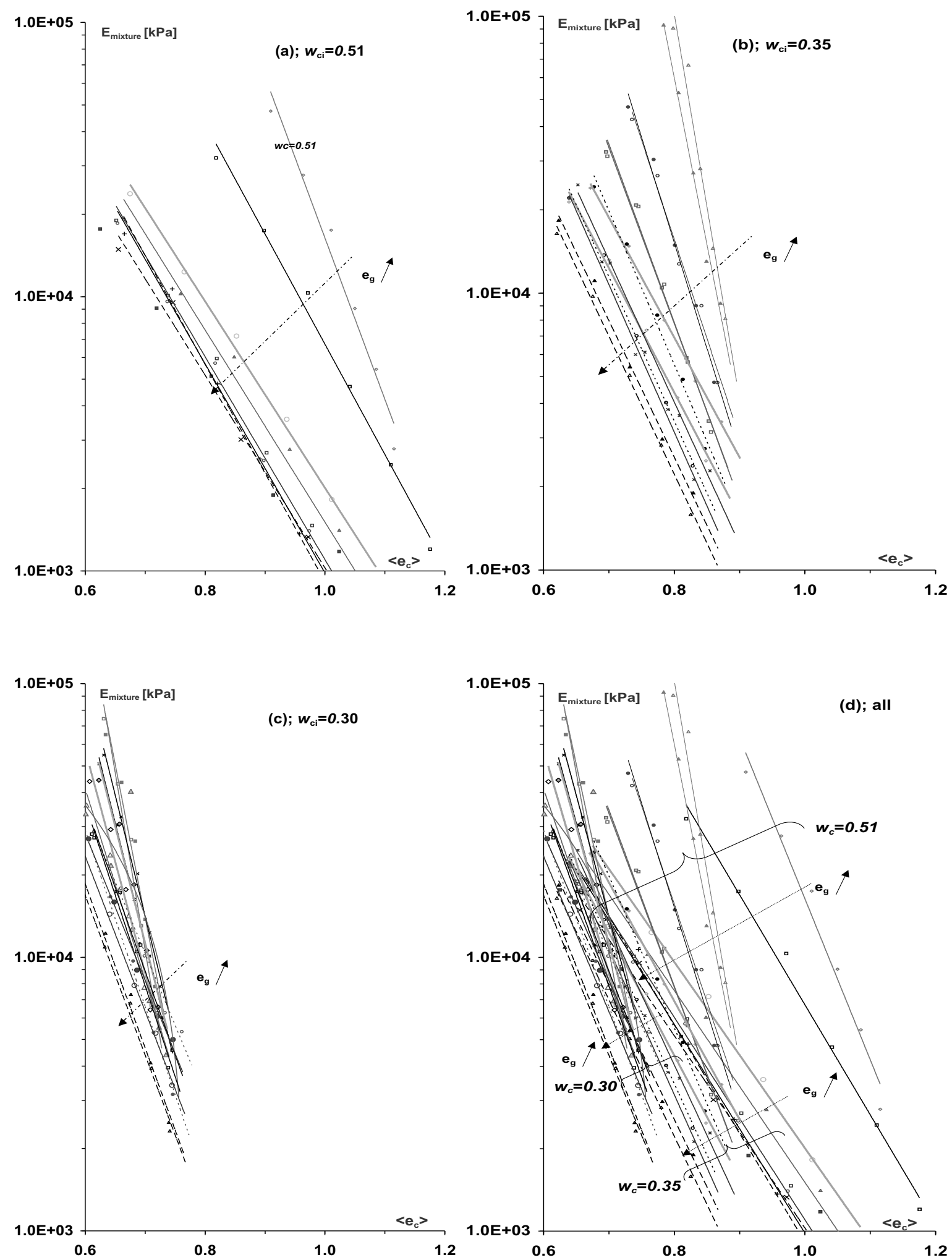

Fig. 8 - The oedometric tangent modulus $\log \left(E_{\text {oed }}\right)$ of the mixtures versus the average void ratio of the clay paste $<e_{c}>$ parameterized by $e_{g}$. The three groups of curves correspond to mixtures initially made of clay paste at the liquid state (a), at an intermediate state (b), at a quasi-plastic state (c). The data of all samples are plotted together on (d). 

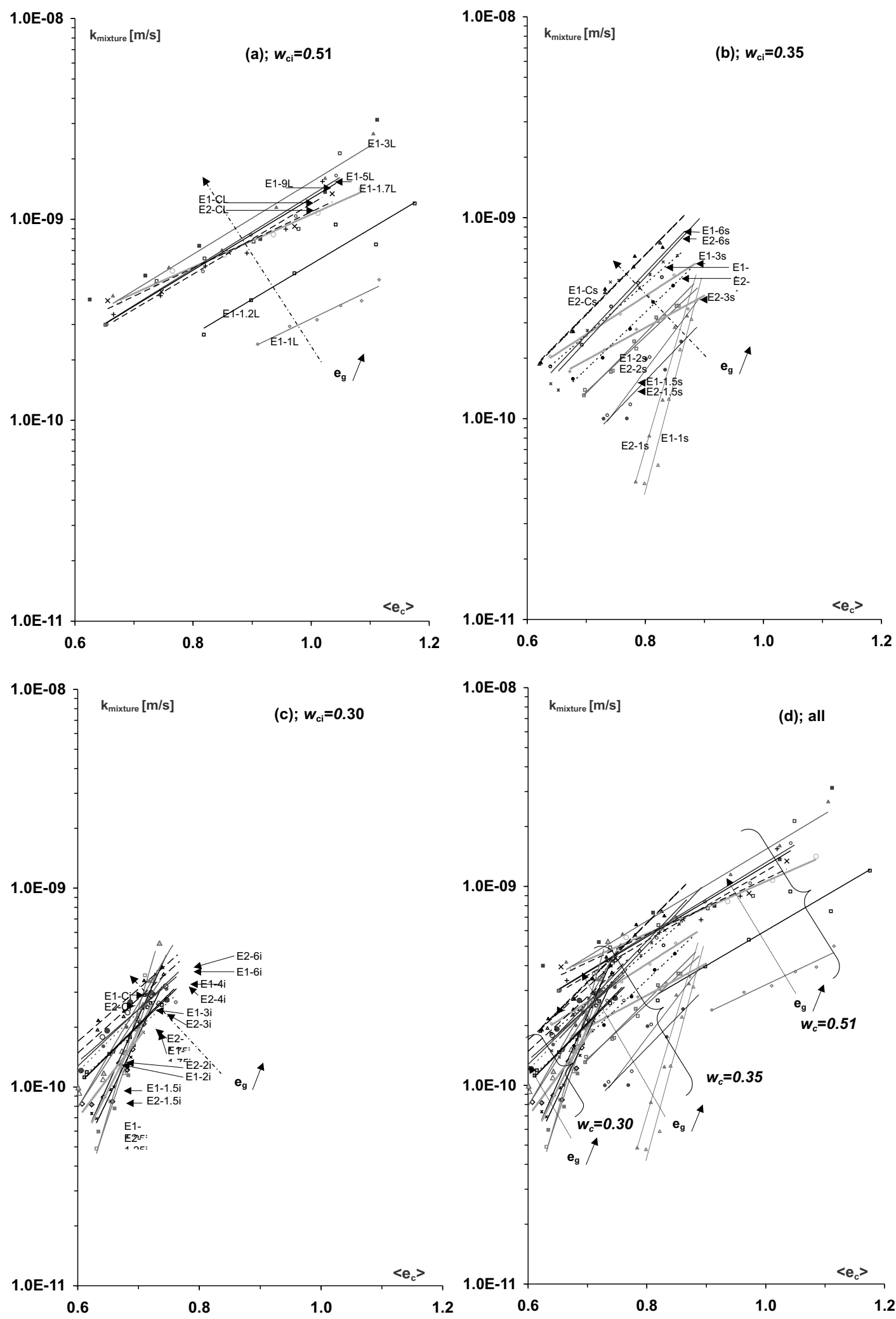

Fig. 9 - Permeability of the mixtures versus $<e_{c}>$ parameterized by $e_{g}$. Mixture initially made of clay paste at the liquid state (a), at an intermediate state (b), at a quasi-plastic state (c). The data of all samples are plotted together on (d). 
negligible and the mixture permeability is assimilated to the soil permeability. Figure 9 shows the variation of $\log (K)$ with $<e_{c}>$ for different $e_{g}$. A linear trend is observed with a slope that decreases as $e_{g}$ increases, according to the physical intuition. It is interesting to note that the curves present the same general trends as observed for the tangent oedometric modulus.

For mixtures with dispersed grains $\left(e_{g}>2 e_{\max }\right)$ or made of paste at the liquid state, $\log (K)$ can be reasonably deduced from $\log \left(K_{\text {paste }}\right)$ by a translation factor depending on $e_{g}$ only, following the expression:

$$
K=H\left(e_{g}\right) \cdot K_{\text {paste }}\left(e_{c}\right)
$$

Consequently, as for the constrained modulus, the mixture permeability can be decoupled into the product of the clay paste permeability by a pure geometrical factor related to grain concentration. For instance, considering mixtures prepared with paste at the liquid state:

$$
K_{\text {paste }}=10^{-9} 10^{2\left(1-e_{c}\right)}
$$

$H\left(e_{g}\right)$ lies in between 1 and 3.

Mixtures with closer grains $\left(e_{g}<2 e_{\max }\right)$ and less liquid paste are much less permeable, and the influence of $\left\langle e_{c}\right\rangle$ and $e_{g}$ cannot be decoupled. In those cases, the experimental results may be summarized by the following empirical relationships:

$$
\begin{gathered}
\log (K)=a^{\prime}\left(e_{g}\right)-b^{\prime}\left(e_{g}\right) \log \left(K_{\text {paste }}\right) ; \\
\quad \text { or } \quad K=G^{\prime}\left(e_{g}\right)\left[K_{\text {paste }}\right]^{b^{\prime}\left(e_{g}\right),}
\end{gathered}
$$

with $1 / 3<b^{\prime}\left(e_{g}\right)<1$. The strong reduction of permeability and its interdependence with the grain concentration, argues in favour of a structuring process previously mentionned. Indeed, the significant reduction in permeability can be interpreted as being caused by the presence of a network of denser (and, thus, less permeable) zones within the clay paste.

\section{BASIC MODELLING IN THE FRAMEWORK OF HOMOGENIZATION}

Phenomena in heterogeneous media can be upscaled and formulated in terms of macroscopic behaviour, provided that a condition of scale separation is fulfilled. This latter condition requires that the medium morphology is sufficiently regular to be described by a Representative Elementary Volume REV and that the characteristic size of the phenomena is much larger than the REV size. These two conditions are respected in the present work.

For linear phenomena, the homogenization of periodic media (Sanchez-Palencia 1980) - based on a two scale asymptotic expansions of both physical variables and differential operators - provides a rigorous theoretical framework to justify the existence of the macroscopic behaviour and to determine its features and limits of validity.

Non-linear phenomena drastically increase the theoretical difficulties, so that only sparse results for specific cases are available (Suquet and Zaoui 1997). A way to relax this difficulty without missing the theoretical tools of the periodic homogenization is to linearize the problem. At the expense of simplifying assumptions, the homogenization can, then, be applied to determine the incremental tangent macroscopic properties.

This section aims at identify up to which extent the usual and tangent homogenization techniques are able to describe reasonably the mixture permeability and tangent compressibility. A corollary aim is also to point out the domain of interest and the limitations of such approaches by using the experiments described in this work for qualitative and quantitative comparisons.

\section{Modelling of Permeability}

The determination of the permeability of a composite material made of a permeable media (the clay paste characterized by $K_{\text {paste }}$ ) and impervious grains at a granular void ratio $e_{g}$ is a classical linear problem of homogenization. By assimilating the mixture to a bi-composite with $K_{\text {paste }}$ constant and isotropic (implying that $e_{c}$ is considered homogeneous in the REV, i.e. $e_{c},=<e_{c}>$ ), and assuming in addition the mixture being isotropic, the homogenization procedure leads to express the permeability of the mixture $K$ as:

$$
K=K_{\text {paste }} \cdot H
$$

where $H$ depends only on the cell geometry. In absence of more details about grain arrangement in the REV, $H$ will be expressed as a function of the most basic geometrical information: the volume ratio between the two constituents $e_{g}$. To estimate $H\left(e_{g}\right)$, assumptions must be done on the microstructure. For simplicity, two cases will be considered (Fig. 10): 
- the idealized case of a 1D stratified sand-clay paste microstructure. In this case, the permeability in the direction of the clay layers is given by:

$$
K=K_{\text {paste }} \cdot(1-G)=K_{\text {paste }} \frac{e_{g}}{1+e_{g}}
$$

- a more realistic 3D geometry suggested by the observation that the microstructure is essentially made of grains coated by the clay paste. For such configuration, the form factor corresponding to spherical grains dispersed in the clay paste can be assessed by using a self-consistent approach based on a pattern formed by a bi-composite sand/paste sphere (Hashin 1968). The expression is:

$$
K=K_{\text {paste }} \frac{e_{g}}{\frac{3}{2}+e_{g}}
$$

The similarity between Equation (15) and the empirical equation (13) indicates that the assumption of constant $e_{c}$ within the REV is in accordance with the experience for the case of mixture with $e_{g}>2 e_{\max }$.

Conversely, the discrepancy between Equation (15) and the power law observed experimentally (Equation 14) indicates that the assumption of an homogeneous clay paste within the REV is missed for $e_{g}<2 e_{\max }$. For quantitative purpose, a comparison of the theoretical and experimental laws are drawn in Figure 10. The progressive departure of the curves as $e_{g}$ decreases confirms the previous remark and suggests the occurrence of structuring phenomena for $e_{g}<2 e_{\max }$.

From a theoretical point of view, the structuring effect can be modelled by representing the mixture by a composite with inhomogeneous matrix (instead of a bicomposite). However, the necessity to known the local values of the permeability within the REV makes the problem much more complex in practice.

\section{Modelling of Oedometric Tangent Modulus}

As already mentioned, the mixture compression behaviour relies on a non-linear hardening mechanism in the clay paste surrounding the grains. A rigorous treatment by homogenization would be extremely complex since, at each loading stage, the inhomogeneous stress distribution modifies the local properties of the clay paste within the REV. Thus, the derivation of the macroscopic behaviour would require an incremental homogenization procedure. A new step of calculation requires the construction of a new REV with properties determined by the previous steps and accounting for the heterogeneous state of the clay paste. Note also that, conversely to the linear case, there is no proof of the uniqueness of the local solution in the REV until now.

In this context, no theoretical derivation of the uniqueness of the local solution will be looked for, but one will rely on the fairly good experimental repeatability to assume its existence. Notice that this assumption is necessary to justify the search of a macroscopic description.

To reduce the complexity of the local problem, three successive simplifying assumptions will be introduced.

- First, the tangent homogenization approach is considered. It considers a fictitious REV made of elastic materials whose properties matches the tangent properties of the real material in the REV. The application of the homogenization method on the fictitious REV leads to the derivation of the tangent macroscopic properties of the real media. Although simplified, this tangent method remains complex because of the general anisotropy of the tangent behaviour. As a matter of fact, if the non linear constitutive law is expressed by:

$$
\sigma=\mathbf{L}(\mathbf{E}): \mathbf{E}
$$

where $\mathbf{E}$ is the strain tensor, the tangent behaviour reads:

$$
d \sigma=\mathbf{L}_{t}(\mathbf{E}): d \mathbf{E}
$$

And, from the tensor representation theorem, (Boelher 1987), as $\mathbf{E}$ is generally anisotropic, the tangent tensor $L_{t}(\mathbf{E})$ is also anisotropic.

- The second simplifying assumption is that the non-linear behaviour only depend on the isotropic invariant of $\mathbf{E}$, i.e., on the volume variation, so that the tangent behaviour can be considered isotropic. In this case, the tangent macroscopic properties could be derived from calculations on a REV with heterogeneous but isotropic and elastic matrix. 


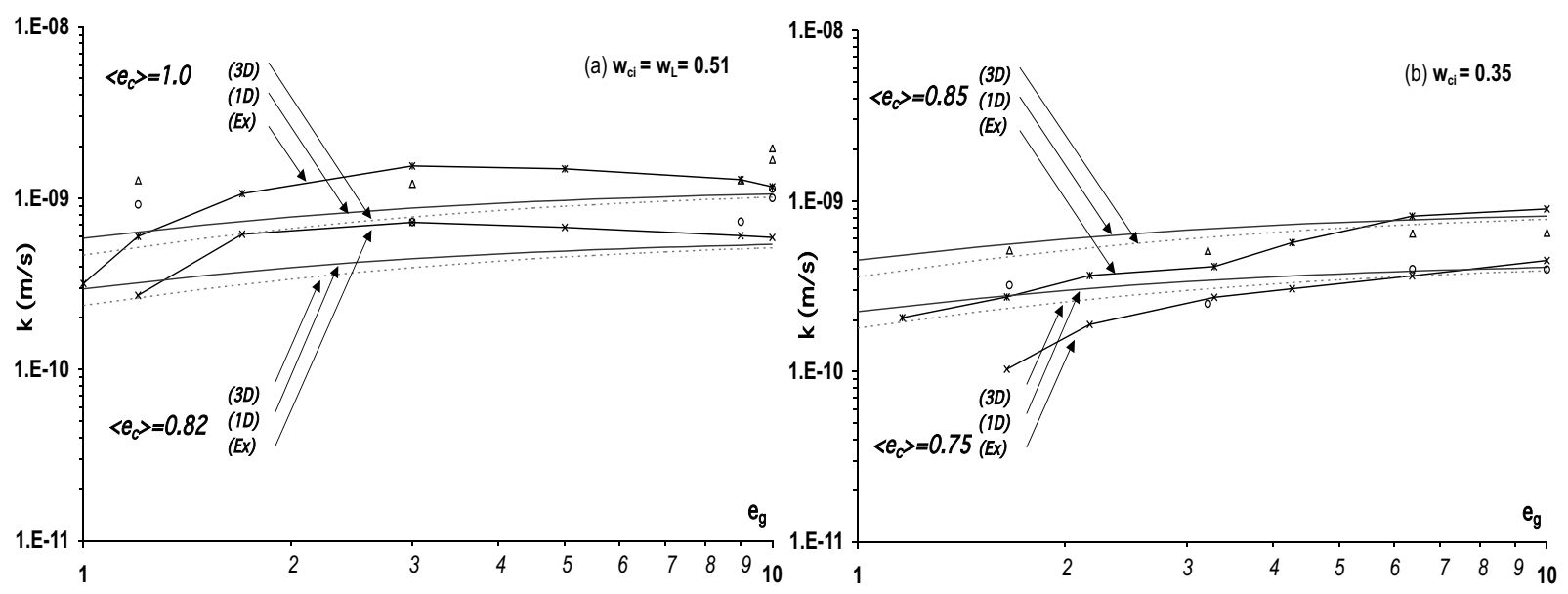

Stratified model (1D)

Self-consistent model (3D)
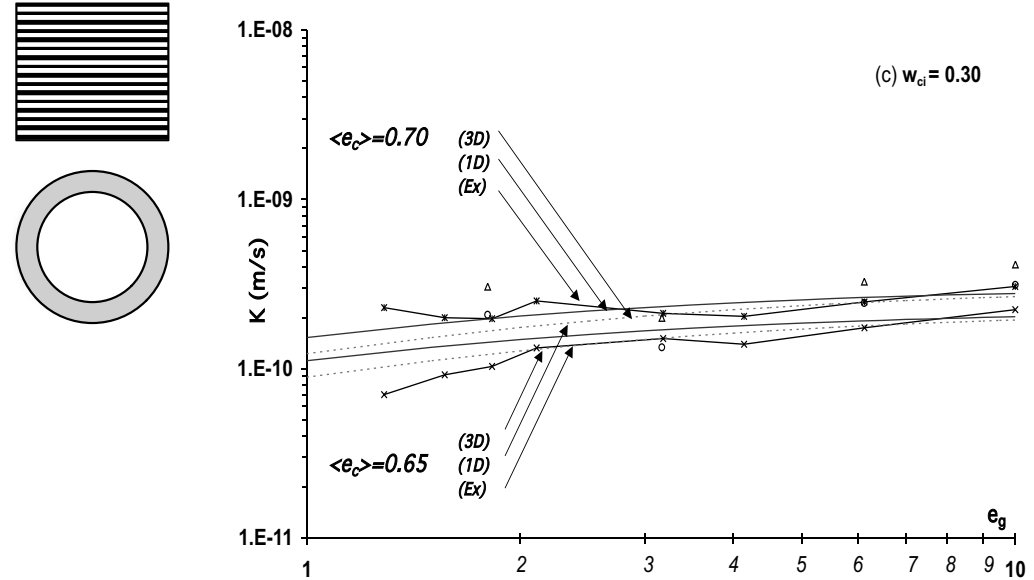

Fig. 10 - Permeability versus the granular void ratio: comparison between theoretical expressions (assimilating the mixture to a 1D or 3D bi-composite) and experimental values.

However, the necessity to specify the local elasticity tensor within the REV makes the problem still complex.

- The third simplifying assumption states an homogeneous volume variation within the clay paste (then $e_{c}$ equals $\left\langle e_{c}>\right.$ ). Then, the macroscopic tangent behaviour can be estimated from the basic homogenization of a bi-composite made of rigid inclusions and an homogeneous isotropic matrix. This leads to express the oedometric modulus in the form (Kacprzak 2006):

$$
E_{\text {oed }}=E_{\text {paste }}\left(<e_{c}>\right) A\left(e_{g}, v\right)
$$

where $A$ is a dimensionless factor depending on the cell geometry (in that case on $e_{g}$ ) and on the Poisson ratio $v$.
The modulus of a 1D idealized stratified sand-clay paste microstructure is, in the direction perpendicular to the clay layers:

$$
E_{\text {oed }}=\frac{E_{\text {paste }}}{1-G}=E_{\text {paste }} \frac{1+e_{g}}{e_{g}}
$$

For spherical grains dispersed in the clay paste, the form factor can be assessed analytically by a self-consistent approach based on a pattern constituted by a bi-composite sand/paste sphere (Christiensen and Lo 1979). The theoretical value of $A\left(e_{g}, v\right)$ slightly depends on the Poisson ratio, (Kacprzak 2006).

These estimates of tangent modulus (16) are qualitatively in accordance with the experimental results established for mixtures with sufficiently dispersed grains $\left(e_{g}>2 e_{\max }\right)$, over the whole loading range. From 

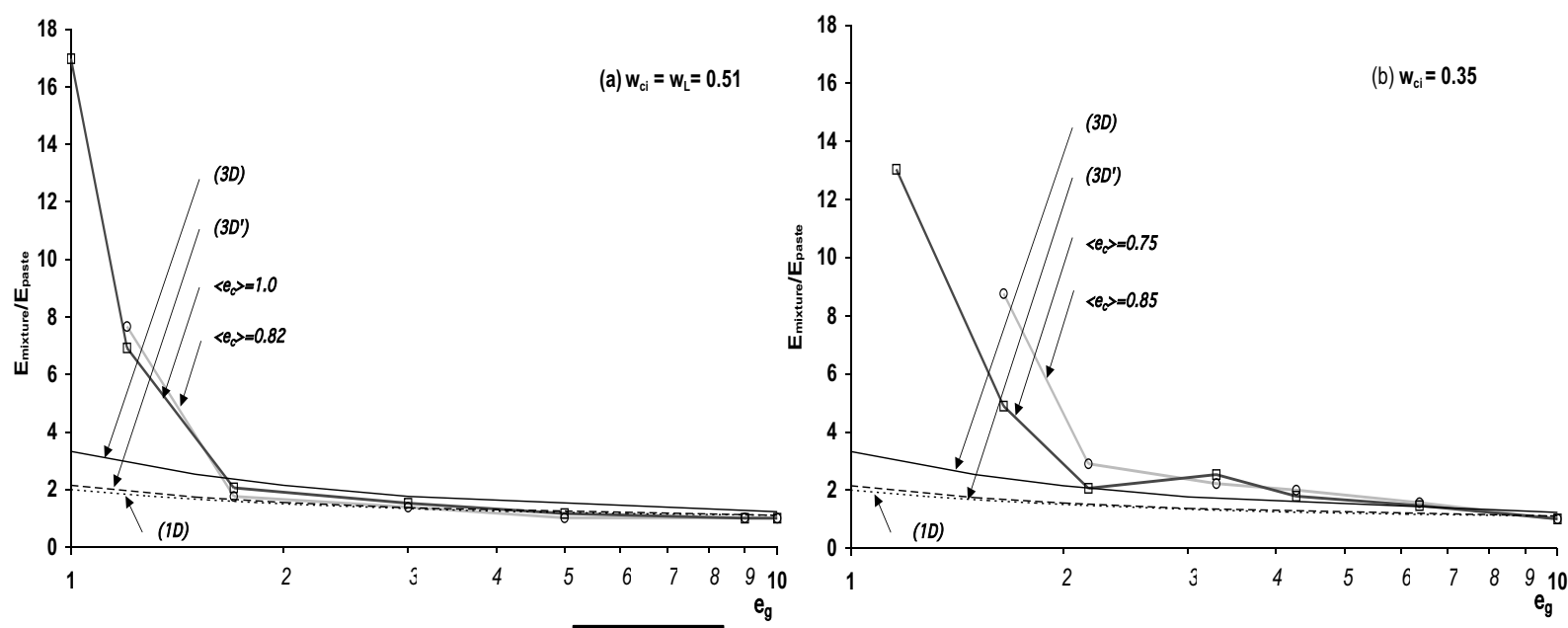

Stratified model (1D)

\section{Self-consistent} tangent model

$$
\begin{aligned}
& v=0(3 D) \\
& v=0.49\left(3 D^{\prime}\right)
\end{aligned}
$$

\section{Experiments $\left(<\mathrm{e}_{\mathrm{c}}>\right)$}

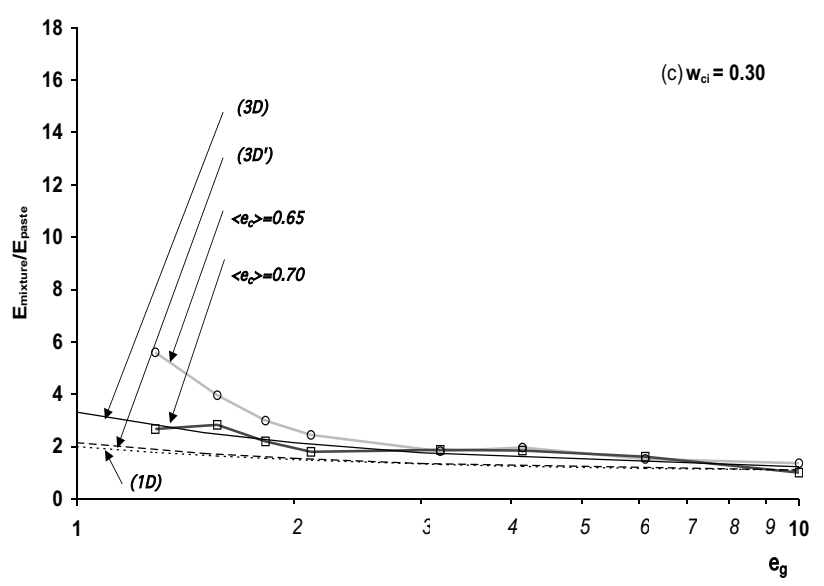

Fig. 11 - Oedometric tangent modulus. Comparison of the ratio $E_{\text {oed }} / E_{\text {paste }}$ deduced from experimental data with those given by tangent homogenization.

a quantitative point of view, a reasonable agreement is also observed (Fig. 11) for granular void ratio above the threshold $2 e_{\max }$.

However, this rudimentary analysis does not give neither qualitative nor quantitative results in agreement with the experimental results obtained on the mixtures with $e_{g}<2 e_{\max }$. As for the permeability, this fact is an indication of the effect played by both structuring and skeleton effects.

\section{CONCLUSION}

The response of mixtures of sand and saturated kaolin paste has been studied in the oedometer for different states of the clay paste (function of the initial water content) and different sand concentrations. Results have been drawn as a function of two volumetric state param- eters, the clay void ratio $e_{c}$ and the granular void ratio $e_{g}$, instead of the overall void ratio parameter classically used in soil mechanics. Results have been interpreted by considering the material as a composite made of a non-linear and permeable matrix (the kaolin paste) and rigid and impervious inclusions (the sand grains). The final aim of this study is to investigate the possibility to build by homogenization a macroscopic description related to a strongly non-linear local behaviour where volume variation is an essential feature.

Oedometric loading and permeability test results highlight the key role of the deviatoric strength of the clay paste in the perturbations introduced by the grains. They also point out a threshold of granular void ratio of about $2 e_{\max }$, below which both structuring and skeleton effect influences the modulus and the permeability. In addition, it has been shown that, as its constituents, 
the mixtures respect the classical logarithmic compression behaviour. Finally, the good repeatability of the results provides, in some way, an experimental proof of the uniqueness of the solution at the local scale (at least statistically), which justifies the search of a macroscopic description.

Incidentally, the structuring effect explains possibly the higher inefficiency of the static uniaxial compaction with respect to the dynamic one. Indeed, the rotation of the principal stresses associated to the dynamic or rolling compaction imposes the stress paths to move and, thus, avoid the construction of stable hardening force chains that channel the stress flux. Location and orientation of the denser zones are constantly redistributed in the material and there is, consequently, no creation of stiffer material response in the preferential direction of the load.

At the light of these experiments, the usual and tangent homogenization processes (with strongly simplifying assumptions to make the problem manageable) have been applied to estimate the mixture permeability and tangent compressibility. Qualitative and quantitative comparisons with experiments show that this approach reasonably succeeds to capture the macroscopic properties over the whole range of loading when the granular void ratio is larger than the threshold of $2 e_{\max }$, but fails in other cases. For these latter cases, the structuring and/or skeleton effect plays a significant role and must be taken into account at the local scale.

\section{RESUMO}

O estudo lida com o comportamento de misturas compostas por areia e uma pasta de caulinita considerada um material composto feito de uma matriz (caulinita) permeável e deformável (com comportamento não-linear) com inclusões rígidas e impermeáveis (grãos de areia). Testes de permeabilidade e odométricos conduzidos nestas misturas enfatizam o papel chave de estado da pasta argilosa e mostram a existência de uma concentração crítica de grãos de areia com efeito estruturante que influencia o módulo e a permeabilidade. Sob a luz destes experimentos o processo de homogeneização usual e tangente (com hipóteses simplificadoras para tornar o problema tratável) foi aplicado para estimar a permeabilidade da mistura e a compressibilidade tangente. Comparações qualitativas e quantitativas com dados experimentais apontam o domínio de interesse bem como a limitação destas abordagens.
Palavras-chave: homogeneização, comportamento nãolinear, misturas de areia-argila, permeabilidade, módulo tangente, compactação, endurecimento.

\section{REFERENCES}

AFNOR NF P94-093. 1993. Détermination des références de compactage d'un matériau. Essai Proctor normal. Essai Proctor modifié. Norme Française.

AFNOR XP P94-090-1. 1997. Essai oedométrique. Essai de compressibilité sur matériaux fins quasi saturé avec chargement par paliers. Norme Française.

AFNOR XP CEN ISO/TS 17892-11. 2005. Détermination de perméabilité à charge constante et à charge variable décroissante. Norme Française.

BoelHer J-P. 1987. Applications of Tensor Functions in Solid Mechanics. CISM Courses and Lectures, 292, Springer Verlag, Wien, New York, 299 p.

CHRISTENSEN RM AND Lo KH. 1979. Solutions for effective shear properties in three phase sphere and cylinder model. J Mech Phys Solids 27: 315-330.

Georgianou V, Burland J and Hight D. 1990. The undrained behaviour of clayed sands in triaxial compression and extension. Geotechnique 41(3): 383-393.

HASHIN Z. 1968. Assessment of self consistent scheme approximation: Conductivity of particulate composites. J Comp Mater 2: 284-304.

KACPRZAK G. 2006. Etude du comportement mécanique des mélanges sable/argile. PhD ENTPE/INSA.

Mitchell JK. 1976. Fundamentals of soil behaviour. J Wiley \& Sons, New York.

SANCHEZ-PALENCIA E. 1980. Non-homogeneous media and vibration theory. In: LeCTURES Notes IN PHYSICS, Springer-Verlag, Berlin, vol. 127, 396 p.

SUQueT P AND ZAOUI A. 1997. Continuum micromechanics. Springer, Wien, New York, 247 p.

Wood DM. 1990. Soil behaviour and critical state soil mechanics. Cambridge University Press, 462 p.

WOOD DM AND KUMAR GV. 2000. Experimental observation of behaviour in heterogeneous soils. Int J Cohesive Frictional Materials 5: 373-398. 